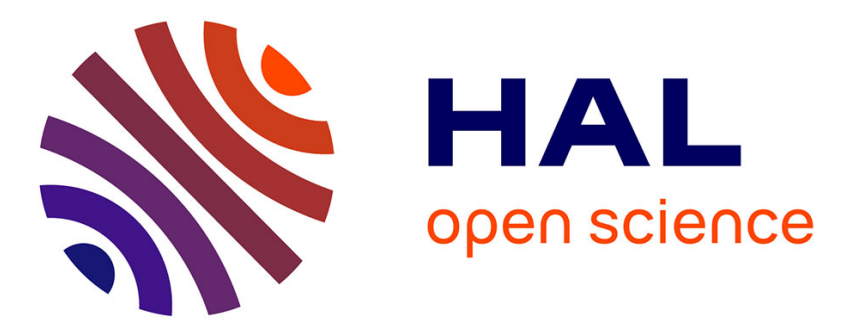

\title{
Effect of multiperforated plates on the acoustic modes in combustors
}

Elsa Gullaud, Simon Mendez, Claude Sensiau, Franck Nicoud, Thierry Poinsot

\section{To cite this version:}

Elsa Gullaud, Simon Mendez, Claude Sensiau, Franck Nicoud, Thierry Poinsot. Effect of multiperforated plates on the acoustic modes in combustors. Comptes rendus de l'Académie des sciences. Série IIb, Mécanique, 2009, 337 (6-7), pp.406-414. 10.1016/j.crme.2009.06.020 . hal-00803809

\section{HAL Id: hal-00803809 \\ https://hal.science/hal-00803809}

Submitted on 22 Mar 2013

HAL is a multi-disciplinary open access archive for the deposit and dissemination of scientific research documents, whether they are published or not. The documents may come from teaching and research institutions in France or abroad, or from public or private research centers.
L'archive ouverte pluridisciplinaire HAL, est destinée au dépôt et à la diffusion de documents scientifiques de niveau recherche, publiés ou non, émanant des établissements d'enseignement et de recherche français ou étrangers, des laboratoires publics ou privés. 


\title{
Effect of multiperforated plates on the acoustic modes in combustors
}

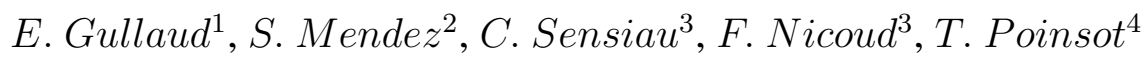 \\ ${ }^{1}$ SNECMA, Villaroche, France \\ ${ }^{2}$ CERFACS, Toulouse, France \\ ${ }^{3}$ University Montpellier II, Montpellier, France \\ ${ }^{4}$ CNRS IMF Toulouse, France
}

\begin{abstract}
The analytical model derived by Howe [1] assessing the acoustic effect of perforated plates has been implemented in a 3D Helmholtz solver. This solver allows to compute the acoustic modes of industrial chambers taking into account the multiperforated plates present for the cooling of the walls. An academic test case consisting of two coaxial cylinders, with the inner one being perforated is used to validate the implementation in the general purpose AVSP code. This case is also used to show the effects of the presence of the plates. In particular, the sensitivity of the acoustic damping to the bias flow speed will be studied. A maximum absorption speed is shown, and the behaviour towards an infinite speed will be illustrated by the academic case. Computations are also conducted in the case of an industrial helicopter chamber. The value of the maximum absorption speed is discussed to explain why the modes are in fact not much absorbed by the perforated plates, and that the frequencies are the same as for walls.
\end{abstract}

\section{INTRODUCTION}

Multiperforated plates (MP) are widely used in the combustion chambers of turbofan engines to cool the walls of the chambers which are submitted to high temperatures [2]. These plates consist of submillimeter apertures, across which the mean pressure jump forces a cold jet through the holes, from the casing into the combustion chamber. The micro-jets then coalesce to form a cooling film. Due to the tiny diameter of the perforations, the holes can not be meshed for numerical computations. It is therefore necessary to have a model to account for the impact of perforated plates. This problem was encountered when performing computational fluid dynamics calculations [3], [4] but also when computing acoustic modes of a combustion chamber. Indeed, MP are known to have a damping effect on acoustics [5], [1], which is enhanced by the presence of a mean bias flow [6]. Acoustic waves interact with the shear layer, creating a vortex breakdown at the rims of the apertures, which converts part of the acoustic energy into vortical energy.

Howe proposed a model for this phenomenon [1], which will be recalled in section I. This model provides the acoustic impedance of a multiperforated plate in the presence of an acoustic wave and is well adapted to be inserted in the Helmholtz solver. It was validated, showing good agreement with experiments [6]. Improvements of this model have been made to take into account the thickness of the plate [7] and the interaction between the apertures [8]. Studies of the parameters influencing the sound absorption have been conducted [6]. In the present study, the implementation of Howe's model in the Helmholtz solver AVSP [9], [10] is presented. AVSP solves the eigenvalue problem related to the wave equation in the frequency domain, and is able to provide the acoustic modes of a combustion chamber. With the implementation of Howe's model, it is now possible to compute the acoustic modes of a chamber, taking into account the multiperforated plates. After a brief description of Howe's model in section I, the coding is validated by comparing AVSP results and the analytics on an academic test case in section II. A study of the influence of the parameters is also conducted in this section. The computations are then performed in section III on a real industrial chamber.

\section{HOWE'S MODEL IN AVSP}

Howe's approach is the most classical model used to represent the behaviour of a multiperforated plate with bias flow and submitted to an acoustical excitation. Let's consider an array of circular perforations of diameter $2 a$, with an inter-orifice spacing $d$, through which a mean flow of speed $U$, parallel to the apertures axis is imposed (see Fig. 1). When an acoustic perturbation is imposed, Howe's model can represent the behaviour of a multiperforated plate under the following hypotheses [1]: 
- The acoustic excitation is at a low frequency, so that the wavelength is much larger than the orifice radius.

- The flow has a high Reynolds number, the viscosity is then only dominant at the rims of the aperture leading to the shedding of vorticity.

- The Mach number of the mean flow is low, so that the flow is incompressible in the vicinity of the aperture.

- The plate is infinitely thin.

- The aperture spacing is high compared to the aperture radius, so that the interaction between the apertures is negligible.

Acoustic energy is converted into vortical energy, due to the vortex shedding occuring at the aperture rims.

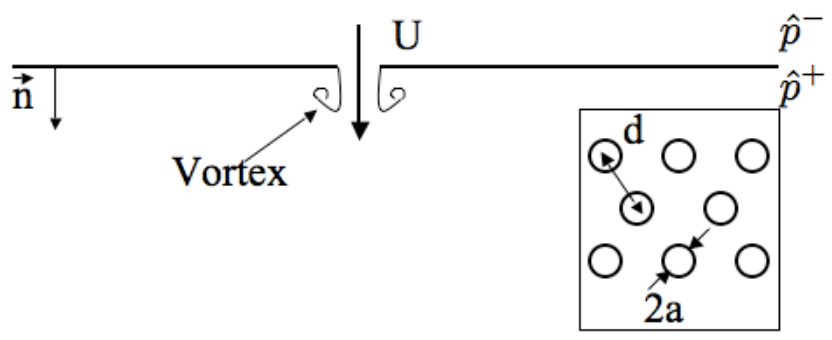

Figure 1 : Array of circular apertures, of diameter $2 a$ and aperture spacing $d$, with a bias flow of speed $U$.

The Rayleigh conductivity $K_{R}$ ([11]) of the aperture, relating the harmonic volume flux $\hat{Q}$ to the acoustic pressure jump across the plate, is defined by

$$
K_{R}=\frac{i \omega \rho \hat{Q}}{\hat{p}^{+}-\hat{p}^{-}},
$$

where $\rho$ is the mean density in the vicinity of the aperture, $\omega$ is the pulsation of the acoustic perturbation and $\hat{p}^{+}$and $\hat{p}^{-}$are the harmonic pressures upstream and downstream of the aperture respectively. We have

$$
\hat{Q}=d^{2} \hat{u}^{ \pm}
$$

where $\hat{u}^{ \pm}$is the acoustic velocity on the plate, equal on both sides. Hence,

$$
K_{R}=\frac{i \omega \rho_{0} d^{2} \hat{u}^{ \pm}}{\hat{p}^{+}-\hat{p}^{-}}
$$

Howe expresses the Rayleigh conductivity for a circular aperture in an infinitely thin plate ([1]) as:

$$
K_{R}=2 a\left(\Gamma_{R}-i \Delta_{R}\right),
$$

where

$$
\Gamma_{R}-i \Delta_{R}=1+\frac{\frac{\pi}{2} I_{1}(S t) e^{-S t}-i K_{1}(S t) \sinh (S t)}{S t\left(\frac{\pi}{2} I_{1}(S t) e^{-S t}+i K_{1}(S t) \cosh (S t)\right)} .
$$

$S t$ is the Strouhal number defined by $\frac{\omega a}{U}$. Using the momentum equation and Eq. (3), we obtain:

$$
\vec{\nabla} \hat{p} \cdot \vec{n}=\frac{K_{R}}{d^{2}}\left[\hat{p}^{+}-\hat{p}^{-}\right]
$$

Eq. (6) is then used as a boundary condition in AVSP. The acoustic pressure gradient can then be expressed as a function of the geometrical parameters $(a$ and $d$ ) and the frequency, and the acoustic pressure jump across the plate. 


\section{AnALYTic VALidation}

\section{II.1 Analytics}

First, an academic test configuration, for which an analytic solution can be derived, is presented. We consider the geometry depicted in Fig. 2. It consists of two coaxial cylinders, the inner one being perforated. The outer radius is $r_{2}$. The perforated plate is located at $r_{1} \cdot r_{1}^{-}$and $r_{1}^{+}$denote the upstream part of the plate and the downstream part respectively.

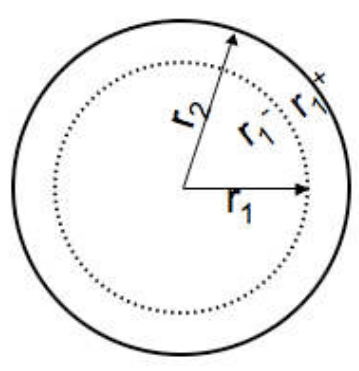

Figure 2 : Academic configuration: cylinder of radius $r_{2}$, with a perforated plate at $r_{1}$.

Let's consider the wave equation written in the frequency domain [12].

The interior of the domain is denoted by $\Omega$, and the boundary by $\delta \Omega$.

$$
\left\{\begin{array}{r}
\Delta \hat{p}+k^{2} \hat{p}=0 \text { on } \Omega . \\
\vec{\nabla} \hat{p} \cdot \vec{n}=0 \text { on } \delta \Omega .
\end{array}\right.
$$

Considering $k^{2}=k_{r}^{2}+k_{z}^{2}$, Eq. (7) can be cast in polar coordinates (Eq. (8)), with $\hat{p}=R(r) \Theta(\theta) Z(z)$ [13].

$$
\frac{1}{R} \frac{d^{2}}{d r^{2}} R+\frac{1}{r R} \frac{d}{d r} R+\frac{1}{r^{2} \Theta} \frac{d^{2}}{d^{2} \theta} \Theta+\frac{1}{Z} \frac{d^{2}}{d z} Z+\left(k_{r}^{2}+k_{z}^{2}\right)=0 .
$$

Since we only consider the radial and azimuthal modes, we have

$$
\frac{1}{R} \frac{d^{2}}{d r^{2}} R+\frac{1}{r R} \frac{d}{d r} R+\frac{1}{r^{2}}\left(\frac{1}{\Theta} \frac{d^{2}}{d^{2} \theta} \Theta+n_{\theta}^{2}\right)+k_{r}^{2}-\frac{n_{\theta}^{2}}{r^{2}}=0 .
$$

In these conditions, the radial part of Eq. (8) can be reduced to a Bessel equation:

$$
\left(\frac{d^{2}}{d r^{2}} R+\frac{1}{r} \frac{d}{d r} R\right)+R \times\left(k_{r}^{2}-\frac{n_{\theta}^{2}}{r^{2}}\right)=0,
$$

whose general solution is of the form:

$$
R(r)=A J_{n_{\theta}}\left(k_{r} r\right)+B N_{n_{\theta}}\left(k_{r} r\right),
$$

where $J_{n_{\theta}}$ and $N_{n_{\theta}}$ are Bessel functions of the $n_{\theta}$ order. In the domain $r \leq r_{1}$, the pressure can be written:

$$
R(r)=A J_{n_{\theta}}\left(k_{r} r\right) .
$$

The Neumann function, which is singular in $r=0$, is put aside. In the domain $r_{1}^{+} \leq r \leq r_{2}$, solutions may be written:

$$
R(r)=B J_{n_{\theta}}\left(k_{r} r\right)+C N_{n_{\theta}}\left(k_{r} r\right) .
$$

A null acoustic speed is imposed on the outer cylinder. Applying the condition $\hat{u}=0$ in $r=r_{2}$, we obtain:

$$
B J_{n_{\theta}}^{\prime}\left(k_{r} r\right)+C N_{n_{\theta}}^{\prime}\left(k_{r} r\right)=0 .
$$

Jump conditions can also be written across the perforated plate:

$$
\hat{p}\left(r=r_{1}^{+}\right)-\hat{p}\left(r=r_{1}^{-}\right)=\frac{i \omega \rho d^{2}}{K_{R}} \hat{u}\left(r=r_{1}^{-}\right),
$$




$$
\hat{p}\left(r=r_{1}^{-}\right)-\hat{p}\left(r=r_{1}^{+}\right)=-\frac{i \omega \rho d^{2}}{K_{R}} \hat{u}\left(r=r_{1}^{+}\right) .
$$

We then obtain the system

$$
[M][X]=0,
$$

where $\mathrm{M}$ is the matrix obtained by using Eq. (14), Eq. (15) and Eq. (16), and given by

$$
\left[\begin{array}{ccc}
0 & J_{n_{\theta}}^{\prime}\left(k_{r} r_{2}\right) & N_{n_{\theta}}^{\prime}\left(k_{r} r_{2}\right) \\
\frac{d^{2}}{K_{R}} k_{r} J_{n_{\theta}}^{\prime}\left(k_{r} r_{1}\right)+J_{n_{\theta}}\left(k_{r} r_{1}\right) & -J_{n_{\theta}}\left(k_{r}\left(r_{1}^{+}\right)\right) & -N_{n_{\theta}}\left(k_{r}\left(r_{1}^{+}\right)\right) \\
J_{n_{\theta}}\left(k_{r} r_{1}\right) & -J_{n_{\theta}}\left(k_{r}\left(r_{1}^{+}\right)\right)+\frac{d^{2} k_{r}}{K_{R}} J_{n_{\theta}}^{\prime}\left(k_{r}\left(r_{1}^{+}\right)\right) & -N_{n_{\theta}}\left(k_{r}\left(r_{1}^{+}\right)\right)+\frac{d^{2} k_{r}}{K_{R}} N_{n_{\theta}}^{\prime}\left(k_{r} r_{2}\right)
\end{array}\right],
$$

and $\mathrm{X}$ is the vector

$$
\left[\begin{array}{l}
A \\
B \\
C
\end{array}\right]
$$

Solving

$$
\operatorname{det}(M)=0
$$

releases the eigenvalues of the configuration.

\section{II.2 RESULTS}

Let us consider the following parameters for the plate: $U=5 \mathrm{~m} / \mathrm{s}, a=3 \mathrm{~mm}$ and $d=35 \mathrm{~mm}, r_{1}=0.2 \mathrm{~m}$ and $r_{2}=0.25 \mathrm{~m}$. The configuration calculated in AVSP contains a tetrahedric mesh of 1186 nodes. The sound speed is uniform and equal to $347 \mathrm{~m} / \mathrm{s}$. The eigenfrequencies are gathered in Table 1 and compared to analytical results obtained by solving Eq. (17). The first three modes are considered. AVSP provides a complex frequency $\operatorname{Re}(f)+i \operatorname{Im}(f)$ where $\operatorname{Re}(f)$ consists of the frequency of the mode, and $\operatorname{Im}(f)$ expresses the amplification rate of the mode. With the adopted convention $p^{\prime}(x, t)=\operatorname{Re}\left(\hat{p}(x) e^{-i \omega t}\right)$, the amplification factor is $e^{2 \pi \operatorname{Im}(f) t}$. From this factor, an amplification rate $\mathcal{A}$ in percent in a period $\mathrm{T}$ can be deduced.

As expected, the eigenfrequencies have a negative imaginary part, which means the pressure fluctuation is damped. AVSP results are in good accordance with the theory. Figures 3 and 4 show the radial profiles of the real and imaginary parts of $\hat{p}$ given by AVSP for the first and second modes. Analytic solutions are also given for comparison. Again, a good accordance is found. Note that the pressure jump across the perforated plate is visible on the real and imaginary parts of the harmonic pressure fluctuations, as well as on the isolines for the first azimuthal mode (Fig. 3).

\begin{tabular}{|c|c|c|c|c|}
\hline & \multicolumn{2}{|c|}{ AVSP results with MP } & \multicolumn{2}{c|}{ Analytics with MP } \\
\hline \hline & $\operatorname{Re}(f)$ & $\operatorname{Im}(f)(\mathcal{A} \%)$ & $\operatorname{Re}(f)$ & $\operatorname{Im}(f)(\mathcal{A} \%)$ \\
\hline$n_{\theta}=1$ & $382.5 \mathrm{~Hz}$ & $\mathbf{- 1 8 . 8} s^{-1}(26.7 \%)$ & $382.56 \mathrm{~Hz}$ & $\mathbf{- 1 8 . 9} s^{-1}(27.8 \%)$ \\
$n_{\theta}=0$ & $534.1 \mathrm{~Hz}$ & $\mathbf{- 9 7 . 5} s^{-1}(68.2 \%)$ & $533.21 \mathrm{~Hz}$ & $\mathbf{- 9 7 . 5} s^{-1}(68.3 \%)$ \\
$n_{\theta}=2$ & $610.48 \mathrm{~Hz}$ & $\mathbf{- 2 1 . 4} s^{-1}(19.8 \%)$ & $611.04 \mathrm{~Hz}$ & $\mathbf{- 2 1 . 6 4} s^{-1}(19.9 \%)$ \\
\hline
\end{tabular}

Table 1 : Comparison of the eigenfrequencies between AVSP and analytics. 


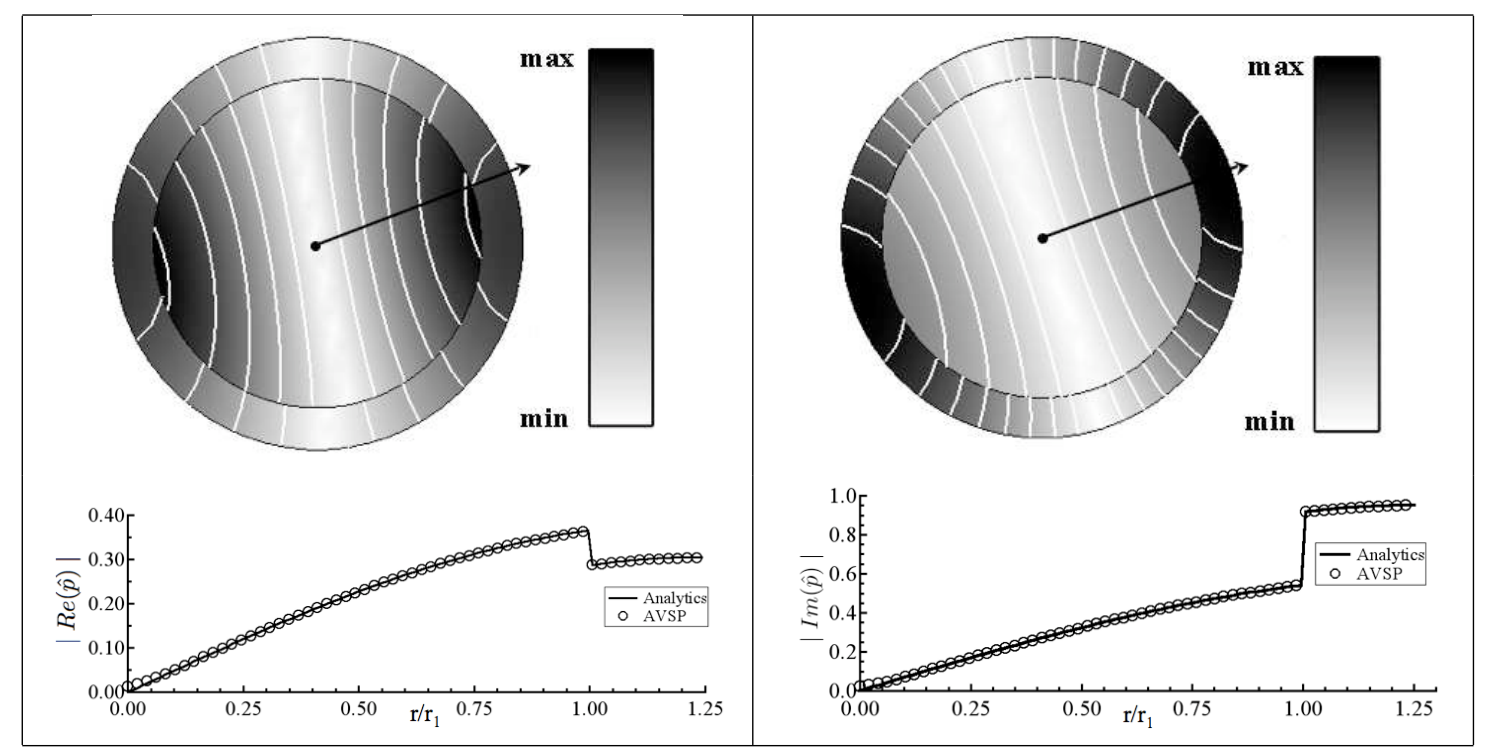

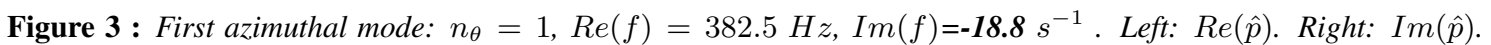
Above: AVSP results. Below : Radial profiles of the real and imaginary part of $\hat{p}$ along the radius represented by the arrow (comparison analytics/AVSP).

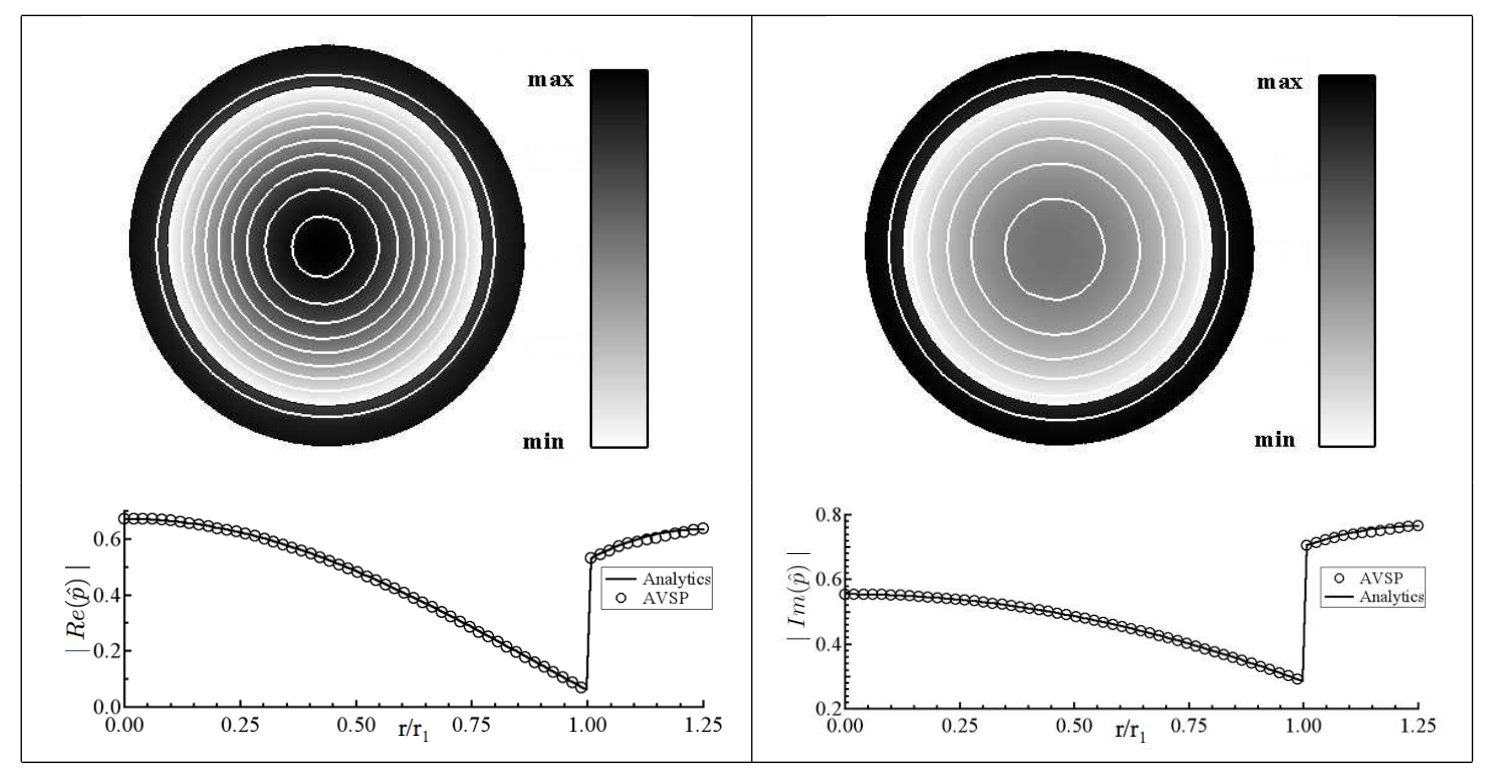

Figure 4 : Radial mode: $n_{\theta}=0, \operatorname{Re}(f)=534.1 \mathrm{~Hz}, \operatorname{Im}(f)=-97.5 \mathrm{~s}^{-1}$. Left: $\operatorname{Re}(\hat{p})$. Right: $\operatorname{Im}(\hat{p})$. Above : AVSP results. Below: Radial profiles of the real and imaginary part of $\hat{p}$ (comparison Analytics/AVSP).

\section{II.3 STUdY OF THE INFLUENCE OF THE PARAMETERS}

The impact of MP is further analysed in this section by comparing the results of four runs in Table 2.

- No plate: the inner cylinder is removed.

- Wall: the inner cylinder is replaced by a impermeable solid wall.

- MP5: the MP inner cylinder is present and the bias flow speed is $U=5 \mathrm{~m} / \mathrm{s}$.

- MP120: the MP inner cylinder is present and the bias flow speed is $U=120 \mathrm{~m} / \mathrm{s}$.

No damping occurs in absence of a MP: $\operatorname{Im}(f)=0$ for the cases "wall" and "no plate". The influence of the mean bias flow speed on the damping is investigated at a fixed porosity $\left(\sigma=\pi a^{2} / d^{2}\right)$. Table 2 shows the comparison of the first azimuthal mode $\left(n_{\theta}=1\right)$, at low bias flow speed $(5 \mathrm{~m} / \mathrm{s})$ and at a high 
bias flow speed $(120 \mathrm{~m} / \mathrm{s})$. The MP has a strong influence on the frequency. Figure 5 shows that not only the frequency tends to the frequency of a wall at a high bias flow speed but also the structure of the mode does. Isolines of the harmonic pressure fluctuations are also plotted for a better understanding of the mode structure.

\begin{tabular}{|c|c|c|c|c|c|c|c|}
\hline \multicolumn{2}{|c|}{ No plate } & \multicolumn{2}{c|}{ MP5, $U=5 \mathrm{~m} / \mathrm{s}$} & \multicolumn{2}{c|}{ MP120, $U=120 \mathrm{~m} / \mathrm{s}$} & \multicolumn{2}{c|}{ Walls } \\
\hline \hline$R e(f)$ & $\operatorname{Im}(f)$ & $\operatorname{Re}(f)$ & $\operatorname{Im}(f)(\mathcal{A} \%)$ & $\operatorname{Re}(f)$ & $\operatorname{Im}(f)(\mathcal{A} \%)$ & $\operatorname{Re}(f)$ & $\operatorname{Im}(f)$ \\
\hline $406.5 \mathrm{~Hz}$ & $0 s^{-1}$ & $382.5 \mathrm{~Hz}$ & $-18.8 s^{-1}(26.7)$ & $247.9 \mathrm{~Hz}$ & $-16.8 s^{-1}(34.7)$ & $246.5 s^{-1}$ & $0 s^{-1}$ \\
\hline
\end{tabular}

Table 2 : Comparison of the first azimuthal mode, without MP, at low bias flow speed, at high bias flow speed, and with a wall. $\sigma=2.3 \%$

Figure 6 shows the evolution of the damping in percent generated by the plate, when the bias flow speed changes between $5 \mathrm{~m} / \mathrm{s}$ and $120 \mathrm{~m} / \mathrm{s}$. For the plate with a $3 \mathrm{~mm}$ radius perforation and a $35 \mathrm{~mm}$ interorifice distance ( $\sigma=2.3 \%$ ), the jet speed corresponding to the maximum absorption is $20 \mathrm{~m} / \mathrm{s}$. Above this value, the damping drops. Another set of parameters is tested here $(\sigma=1.6 \%)$ for which the maximum absorption speed is $12 \mathrm{~m} / \mathrm{s}$. This will be discussed in Section III.
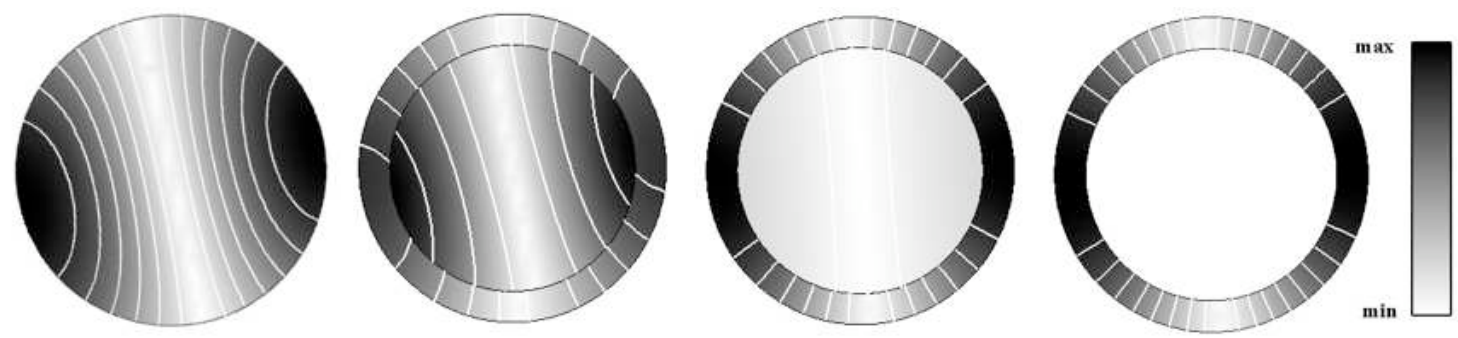

Figure 5 : Evolution of the first mode, without plate, at low (MP5: $f=382.5 \mathrm{~Hz}, \mathcal{A}=26.7 \%$ ) and high bias flow speed (MP120: $f=247.9 \mathrm{~Hz}, \mathcal{A}=34.7 \%)$, and with a wall $(f=246.5 \mathrm{~Hz}, \mathcal{A}=0 \%$ ).

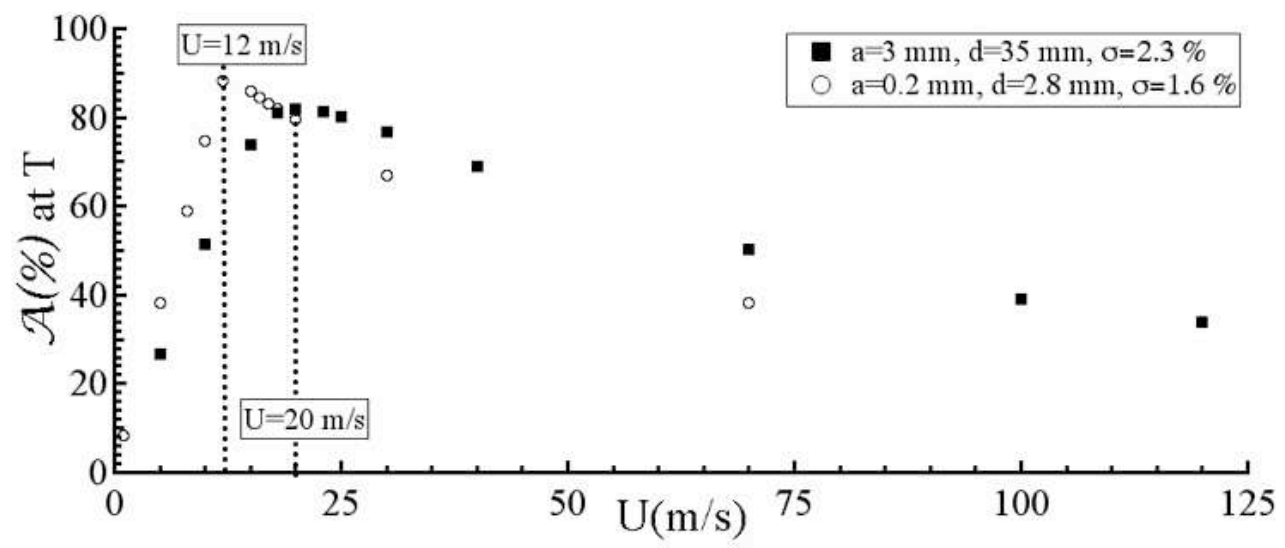

Figure 6 : Evolution of the damping as a function of the bias flow speed $U$, $\sigma$ fixed. 


\section{COMPUTATIONS ON AN INDUSTRIAL HELICOPTER CHAMBER}

Computations are now conducted with AVSP in the case of an actual industrial chamber. This helicopter chamber is a reverse-flow annular chamber fueled by 15 injectors and is equipped with MP for cooling purpose, allowing the fresh air coming from the casing into the chamber to cool the walls. The computational domain is limited here to a $24^{\circ}$ section, corresponding to one injector (Fig. 7). It contains the combustion chamber, the casing and the swirler. The influence of the geometry on the acoustics of this chamber was previously studied [14] and many computational fluid dynamics calculations were conducted [15], [16]. The purpose here is to study the influence of the MP on the acoustics of the chamber. The locations of the MP are given in Fig. 7. The sound speed field is deduced from a previous LES ${ }^{1}$ computation [17] (Fig. 8). A unstructured mesh of 36445 nodes is used in AVSP. Since we only consider a section of the chamber, only longitudinal modes will here be studied. The bias flow speed is calculated from the LES data and the geometrical characteristics of each plate.

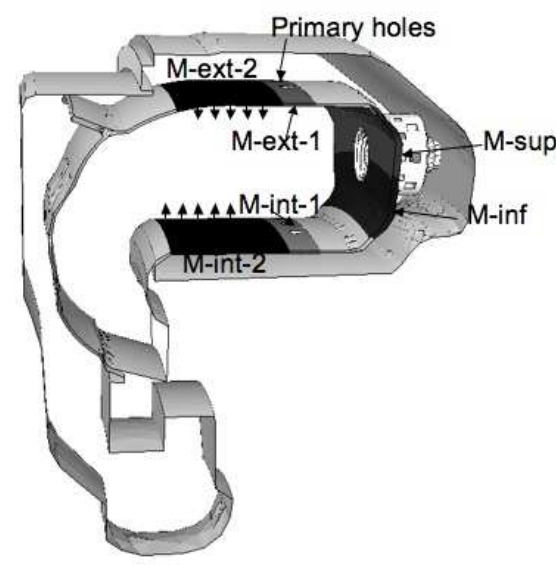

Figure 7 : Location of the MP on the chamber.

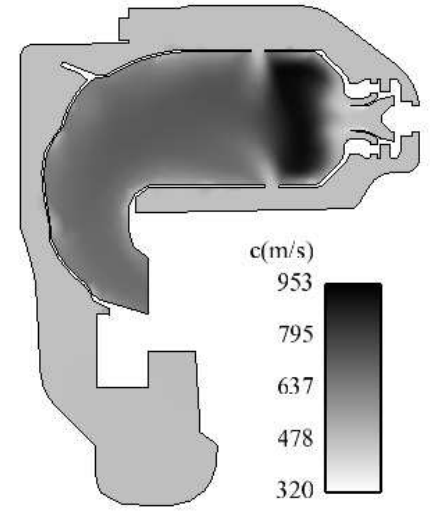

Figure 8 : Sound speed field.

\section{III.1 RESULTS}

To assess the impact of MP in this chamber, we use a reference case when walls are used in place of the MP. Table 3 gives the eigenmodes for the computation with walls and MP. Frequencies are very close. The damping on the first eigenmode is very low $(6.7 \%$ per period $)$.

\begin{tabular}{|c|c|c|c|}
\hline \multicolumn{2}{|c|}{ Walls } & \multicolumn{2}{c|}{ MP } \\
\hline \hline$R e(f)$ & $\operatorname{Im}(f)(\mathcal{A}(\%))$ & $\operatorname{Re}(f)$ & $\operatorname{Im}(f)(\mathcal{A}(\%))$ \\
\hline $506.4 \mathrm{~Hz}$ & $\mathbf{0} s^{-1}(0 \%)$ & 507.04 & $\mathbf{- 5 . 6 0} s^{-1}(6.7 \%)$ \\
$1105.4 \mathrm{~Hz}$ & $\mathbf{0} s^{-1}(0 \%)$ & $1118.7 \mathrm{~Hz}$ & $\mathbf{- 6 1 . 5 4} s^{-1}(29.2 \%)$ \\
\hline
\end{tabular}

Table 3 : Comparison of the first two eigenfrequencies corresponding to the first two longitudinal modes, with walls, and with $M P$.

For a better understanding of this low impact of the MP of the modes on this chamber, we are looking for the maximum absorption speed, for a fixed porosity. In Fig. 6, the set of parameters corresponding to the porosity of the chamber studied here was taken on the cylinder case, and the maximum absorption speed turned out to be $12 \mathrm{~m} / \mathrm{s}$. The maximal absorption occurs here at $U_{m d}$ (Fig. 9), which is the same order of magnitude as for the cylinder. But still the difference is not negligible and shows that the full geometry must be accounted for to predict the maximum absorption speed. At $U=U_{m d}$, the damping is $25 \%$ per period. But at the real bias flow speed of the regime considered here, the damping drops to $6.7 \%$ per period. Indeed, the speed $U_{m d}$ is in the domain where the frequencies tend to be the ones when there is a wall. This shows that acoustics and the cooling process are two decoupled phenomena. For the bias flow speed

\footnotetext{
${ }^{1}$ Large Eddy Simulation.
} 
corresponding to the best cooling of the chamber walls, acoustics are not impacted. Indeed, the behaviour of the chamber is very close to the one when walls are in place of the plates (see Fig. 10). On this figure, the acoustic pressure fields (real part of the acoustic pressure fluctuation) and its isocontours are presented for two different regimes of MP and with a wall. At the maximum absorption speed, the pressure node is not in the same place in the casing and the pressure gradient diminishes in the swirler.

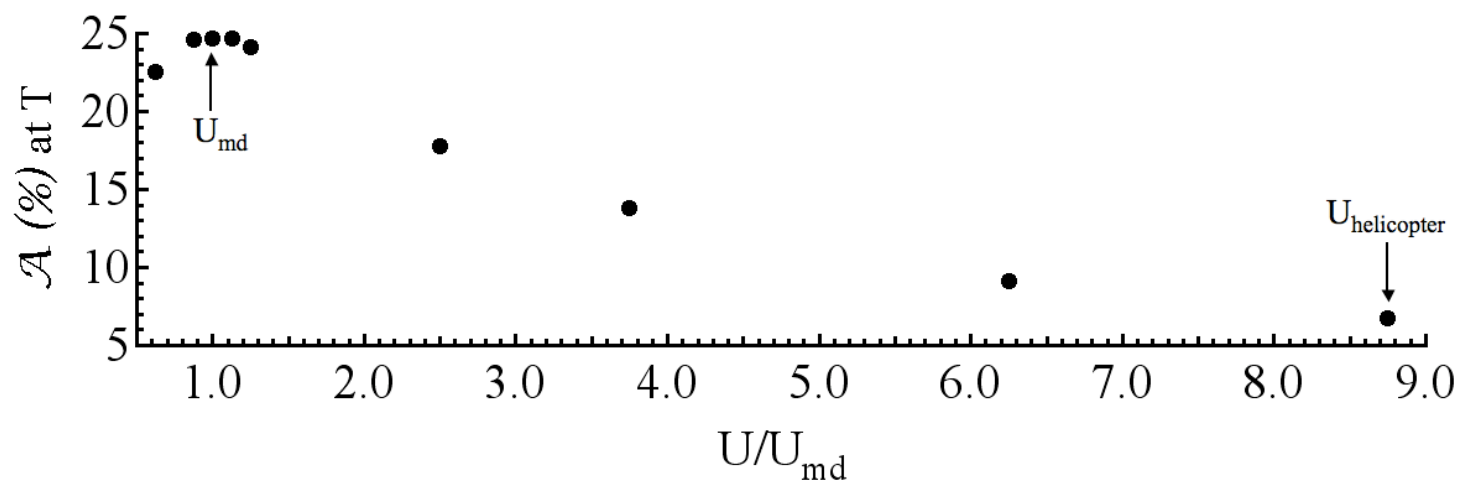

Figure 9 : Evolution of the damping of the first mode at $506.4 \mathrm{~Hz}$ in a period as a function of $U / U_{m d}$.

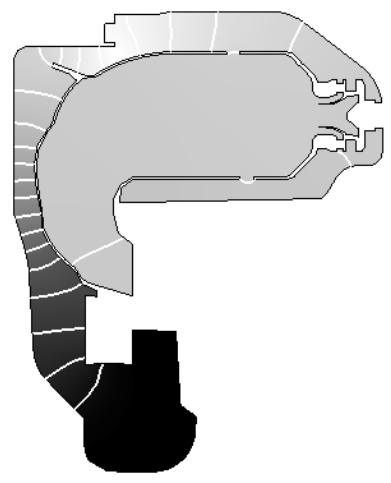

With $M P, U / U_{m d}=1: f=530.9 \mathrm{~Hz}$ $\mathcal{A}=28.6 \%$.

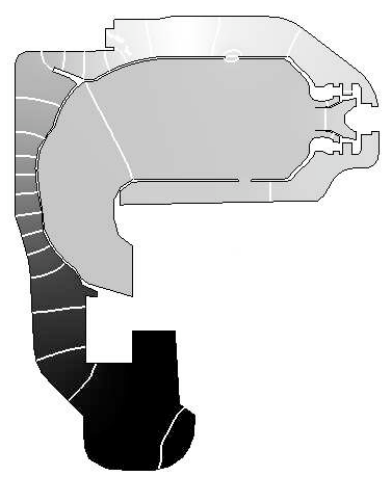

With MP, $U / U_{m d}=8.75: f=507.04 \mathrm{~Hz}$ $\mathcal{A}=6.7 \%$

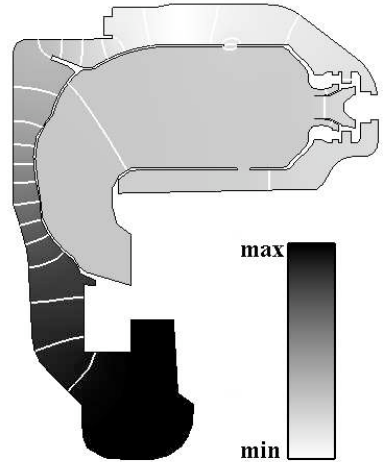

With walls: $f=506.4 \mathrm{~Hz}$ $\mathcal{A}=0 \%$.

Figure 10 : Spatial structure and isolines of $\hat{p}$ for the first mode.

\section{CONCLUSION}

A model for the acoustic behaviour of perforated plates has been implemented in the Helmholtz solver AVSP. This tool allows to take into account MP in computations of the acoustics of a chamber. AVSP predicts damped acoustic modes, in agreement with what could be expected with perforated plates. The frequencies given by the code have a negative imaginary part. But this damping strongly depends on both the parameters of the perforated plate and the bias flow speed. There exists a speed for which the damping reaches its maximum, and beyond this value, the perforated plate tends to behave like a wall and the damping drops. MP are used in industrial chambers in the purpose of cooling the chamber walls. They are not designed to have the best acoustic damping. It was found that with the geometrical characteristics of the perforated plates of the helicopter chamber considered here, and the flow rate injected in the perforations, the speed appears to be far above the maximum absorption speed. Therefore, the damping observed is low, and the frequencies of oscillations are not changed significantly. The cooling of the chamber is carried out without impacting on the chamber acoustics. But with this tool, it is possible to know if by changing the regime of the cooling of the chambers, the acoustics will also get impacted. 
The authors are grateful to the CINES (Centre Informatique National pour l'Enseignement Supérieur) for the access to the supercomputer facilities.

\section{REFERENCES}

[1] M. S. Howe. On the theory of unsteady high Reynolds number flow through a circular aperture. Proceedings of the Royal Society of London. Series A, Mathematical and Physical Sciences, Vol.366( $\left.{ }^{\circ} 1725\right)$ :pages 205-223, 1979.

[2] A. H. Lefebvre. Gas Turbines Combustion. Taylor \& Francis, 1999.

[3] S. Mendez and F. Nicoud. Large-eddy simulation of a bi-periodic turbulent flow with effusion. Journal of Fluid Mechanics, Vol. 598:pages 27-65, 2008.

[4] S. Mendez and F. Nicoud. Adiabatic homogeneous model for flow around a multiperforated plate. AIAA Journal, Vol. 46( $\left.{ }^{\circ} 10\right)$ :pages 2623-2633, 2008.

[5] A. Cummings. Acoustics nonlinearities and power losses at orifices. AIAA Journal, Vol. 22( $\left.{ }^{\circ} 6\right)$ :pages $786-792,1983$.

[6] I. J. Hughes and A. P. Dowling. The absorption of sound by perforated linings. Journal of Fluid Mechanics, Vol. 218:pages 299-335, 1990.

[7] X. Jing and X. Sun. Effect of plate thickness on impedance of perforated plates with bias flow. AIAA Journal, Vol. 38( $\left.{ }^{\circ} 9\right)$ :pages 1573-1578, 2000.

[8] S. H. Lee, J. G. Ih, and K. S. Peat. A model of acoustic impedance of perforated plates with bias flow considering the interaction effect. Journal of Sound and Vibration, 303(3-5):pages 741-752, 2007.

[9] L. Benoit. Prédiction des instabilités thermo-acoustiques dans les turbines à gaz. Phd thesis, Université de Montpellier II, 2005.

[10] F. Nicoud, L. Benoit, and C. Sensiau. Acoustic modes in combustors with complex impedances and multidimensional active flames. AIAA Journal, Vol. 45:pages 426-441, 2007.

[11] L. Rayleigh. The Theory of Sound. Mac Millan (reprinted by Dover, New York, 1945), 1894.

[12] D. T. Blackstock. Fundamentals of Physical Acoustics. John Wiley \& Sons, 2000.

[13] T. Poinsot and D. Veynante. Theoretical and numerical combustion. R.T. Edwards, 2nd edition., 2005.

[14] C. Sensiau. Simulations numériques des instabilités thermoacoustiques dans les chambres de combustion aéronautiques. PhD thesis, Université de Montpellier II, 2008.

[15] G. Staffelbach, L.Y.M. Gicquel, G. Boudier, and T. Poinsot. Large eddy simulation of self excited azimuthal modes in annular combustors. Proc. Combust. Inst., 2008.

[16] G. Boudier, N. Lamarque, G. Staffelbach, L. M. Y. Gicquel, and T. Poinsot. Thermo-acoustic stability of a helicopter gas turbine combustor using large-eddy simulations. International journal of Aeroacoustics, Vol. 8(1):pages 69-94, 2009.

[17] G.Millot. Simulation numérique d'écoulements en présence de plaques multiperforées: étude et validation d'un modèle homogène sous avbp. Technical report, Rapport confidentiel, 2008. 